\title{
Polyethylene Glycol-Conjugated Superoxide Dismutase Improves Recovery of Postischemic Hypercapnic Cerebral Blood Flow in Piglets
}

\author{
JEFFREY R. KIRSCH, MARK A. HELFAER. STEVEN E. HAUN, RAYMOND C. KOEHLER. AND \\ RICHARD J. TRAYSTMAN \\ Department of Anesthesiology/Critical Care Medicine. The Johns Hopkins Medical Institutions. \\ Baltimore. Maryland 21287.4963
}

\begin{abstract}
We tested the hypothesis that administering polyethylene glycol-conjugated superoxide dismutase (PEG-SOD) either before global cerebral ischemia or at the time of reperfusion would alter recovery of cerebral blood flow (CBF; microspheres) response to alteration in arterial $\mathrm{PCO}_{2}$ in pentobarbital-anesthetized, mechanically ventilated piglets (1 to 2-wk old). CBF was measured at an arterial $\mathrm{PCO}_{2}$ of approximately $3.3,5.3$, and $8.7 \mathrm{kPa}$ before and $2 \mathrm{~h}$ after ischemia (10 min aortic cross clamp). To determine the effect of preischemic versus postischemic treatment with PEG-SOD, each piglet received two i.v. drug injections of either $30000 \mathrm{U}$ PEG-SOD or an equal volume of PEG diluent in a randomized, blinded fashion before ischemia and just before reperfusion. Cerebral oxygen consumption and somatosensory evoked potentials were measured during reperfusion as an assessment of brain function. During reperfusion, no group demonstrated delayed hypoperfusion. Hypercapnic CBF was less during reperfusion $(48 \pm 6 \mathrm{~mL} / \mathrm{min} / 100 \mathrm{~g})$ compared with preischemia $(69 \pm 10 \mathrm{~mL} / \mathrm{min} / 100 \mathrm{~g})$ in PEG/PEG-treated piglets. However, hypercapnic $\mathrm{CBF}$ during reperfusion was not different from preischemic values with either preischemic or postischemic PEG-SOD treatment. Improved return of hypercapnic CBF in PEG-SOD-treated piglets was not attributable to improved postischemic cerebral oxygen consumption. Somatosensory evoked potential amplitude was decreased similarly during reperfusion (approximately $25 \%$ of preischemic values) in all groups. We conclude that PEG-SOD alters CBF response to hypercapnia after transient global cerebral ischemia in piglets via a mechanism that is not related to altered oxygen consumption or electrical activity. (Pediatr Res 34: 530-537, 1993)
\end{abstract}

\section{Abbreviations}

CBF, cerebral blood flow

$\mathrm{CMRO}_{2}$, cerebral oxygen consumption

$\mathrm{PaCO}_{2}$, arterial partial pressure of carbon dioxide

$\mathrm{PaO}_{2}$, arterial partial pressure of oxygen

SOD, superoxide dismutase

PEG, polyethylene glycol

PEG-SOD, polyethylene glycol-conjugated superoxide dismutase

MABP, mean arterial blood pressure

ICP, intracranial pressure

CVR, cerebrovascular resistance

Received January 11, 1993; accepted May 13, 1993.

Correspondence and reprint requests: Dr. Jeffrey R. Kirsch. Anesthesiology/ Critical Care Medicine, The Johns Hopkins Hospital, 600 North Wolfe St., Baltimore, MD 21287.4963

Supported in part by NIH Grant NS20020. NS24394, and CIDA NS01225.
SEP, somatosensory evoked potential

SAL, saline treatment

In newborn piglets, the $\mathrm{CBF}$ response to $20 \mathrm{~min}$ of complete compression ischemia is characterized by an initial period of hyperemia followed by hypoperfusion. At $24 \mathrm{~h}$ of reperfusion, CBF has returned to preischemic values (1). In 1- to 2-wk-old piglets, during reperfusion from $10 \mathrm{~min}$ of complete ischemia (aortic cross clamp), there is an initial period of hyperemia but no hypoperfusion within $2 \mathrm{~h}$ of reperfusion (2). In both models and at both ages, there is loss of vasodilation to hypercapnia at a time when CBF has returned to preischemic values (3-5). In newborn piglets, altered reactivity to hypercapnia has been hypothesized to be due to decreased synthesis of vasodilatory prostanoids during hypercapnia rather than an inability of the blood vessels to respond to vasodilatory prostanoids $(4,5)$. In this paradigm, administration of arachidonic acid after ischemia restores arteriolar dilation to hypercapnia (6).

One proposed mechanism for impaired prostaglandin synthesis to hypercapnia is inhibition of cyclooxygenase resulting from production of oxygen radicals (7). Consistent with this hypothesis is the finding of restored pial vessel dilation to hypercapnia when excess substrate (arachidonic acid) is administered (6). In cats, local application of the oxygen radical scavengers SOD and catalase in a cranial window preparation resulted in preservation of vasodilator response to acetylcholine and hyperventilation during reperfusion from $15 \mathrm{~min}$ of ischemia (8). We tested whether administering PEG-SOD to piglets either before global cerebral ischemia or at the time of reperfusion would alter recovery of $\mathrm{CBF}$ reactivity to $\mathrm{CO}_{2}$ and whether recovery in $\mathrm{CO}_{2}$ reactivity could be correlated with recovery of electrical function or $\mathrm{CMRO}_{2}$

\section{MATERIALS AND METHODS}

General preparation. Piglets of either sex were used in this study (Thomas D. Morris Inc., Reisterstown, MD). Piglets (1 to 2 wks old, $2.5-3.5 \mathrm{~kg}$ ) were not removed from the litter until the morning of surgery to avoid hypoglycemia and dehydration. This study was approved by the Johns Hopkins Animal Care and Use Committee. All piglets were anesthetized with pentobarbital (287 $\mu \mathrm{mol} / \mathrm{kg}$ intraperitoneal bolus followed by $35-44 \mu \mathrm{mol} / \mathrm{kg} / \mathrm{h}$ i.v. infusion). The pentobarbital infusion was adjusted before the experimental protocol to avoid tachycardia, hypertension, and purposeful movement to painful stimulation. Before alteration in $\mathrm{PaCO}_{2}$, animals were paralyzed (pancuronium bromide) to overcome ventilatory drive. Each piglet was mechanically ventilated via a tracheostomy (Harvard Respirator model 665, South Natick, MA). Minute ventilation was adjusted to achieve an 
initial $\mathrm{PaCO}_{2}$ of approximately $3.3 \mathrm{kPa}$. After reaching the desired degree of hyperventilation (25-30 breaths/min, $45-70 \mathrm{~mL}$ / breath), supplemental $\mathrm{CO}_{2}$ was added to the inspired gas to maintain $\mathrm{PaCO}_{2}$ between 4.7 and $5.3 \mathrm{kPa}$ during surgical preparation. This procedure permitted hypocapnia to be induced later during the experiment without changes in minute ventilation. Supplemental oxygen was added to the inspired gas to maintain $\mathrm{PaO}_{2}$ between 13.3 and $23.3 \mathrm{kPa}$. Rectal temperature was maintained at $38.0 \pm 0.5^{\circ} \mathrm{C}$ with the use of heat lamps and a heating pad.

Catheters were placed in each femoral vein and right cephalic vein for administration of drugs and fluids. MABP was monitored simultaneously through a catheter inserted into the descending aorta via a femoral artery and through a catheter placed in the right axillary artery. A left atrial catheter was placed via a left thoracotomy for injection of radiolabeled microspheres and for control of left atrial pressure during aortic cross clamp. A catheter placed in the descending aorta via a femoral artery was used to obtain reference withdrawal samples during microsphere injections. Through the left thoracotomy, ligatures were loosely placed around the inferior vena cava (just above the diaphragm), ascending aorta (just distal to the origin of the coronary arteries), and descending aorta (immediately proximal to the level at which the azygos vein crosses the aorta) for subsequent use during the ischemia protocol. After ligatures were secured, the piglet was turned prone and its head stabilized so that the external auditory meatus was approximately $2 \mathrm{~cm}$ above atrial level. The dorsal sagittal sinus was exposed at the level of the coronal suture and cannulated $(0.25-0.5 \mathrm{~cm})$ in the direction of the confluence of the sinuses for cerebral venous sampling. A $2.5-\mathrm{mm}$ Silastic ventricular drain (Cordis Corp., Miami, FL) was placed in the left lateral cerebral ventricle and was used for measurement of ICP.

MABP and ICP were measured continuously with Statham pressure transducers referenced to the level of the left atrium. Cerebral perfusion pressure was calculated as the difference between MABP and ICP. $\mathrm{PaO}_{2}, \mathrm{PaCO}_{2}$, and $\mathrm{pH}$ were measured with Radiometer BMS3 electrodes and analyzer (Radiometer. Copenhagen, Denmark). Arterial and cerebral venous oxygen content, saturation, and $\mathrm{Hb}$ concentration were determined with a CO-oximeter (model 282, Instrumentation Laboratory, Lexington, MA). The blood gas analyzer and CO-oximeter were calibrated routinely throughout each experiment. Arterial glucose concentration was measured with a glucose analyzer (model 23A, Yellow Springs Instruments, Yellow Springs, $\mathrm{OH}$ ).

$C B F$. Regional $\mathrm{CBF}$ was measured using the reference sample radiolabeled-microsphere technique (9). Briefly, $16 \pm 0.5-\mu \mathrm{m}$ diameter microspheres (DuPont-New England Nuclear Products, Boston, MA) were injected into the left atrium and a reference sample was withdrawn from the aortic catheter. For each flow measurement, approximately $1 \times 10^{6}$ spheres were injected into the left atrial catheter and flushed with $5 \mathrm{~mL}$ of normal saline over a period of $20 \mathrm{~s}$. The microsphere injection did not alter MABP. The six isotopes used $\left({ }^{153} \mathrm{Gd},{ }^{114 \mathrm{~m}} \mathrm{In},{ }^{113} \mathrm{Sn},{ }^{103} \mathrm{Ru},{ }^{45} \mathrm{Nb}\right.$, and ${ }^{46} \mathrm{Sc}$ ) in each piglet were injected in random sequence. The brain was sectioned into forebrain and hindbrain (brainstem and cerebellum). The energy windows were set at $68-170 \mathrm{keV}$ for ${ }^{153} \mathrm{Gd}, 174-230 \mathrm{keV}$ for ${ }^{114 \mathrm{~m}} \mathrm{In}, 360-440 \mathrm{keV}$ for ${ }^{113} \mathrm{Sn}, 450-560$ $\mathrm{keV}$ for ${ }^{103} \mathrm{Ru}, 690-820 \mathrm{keV}$ for ${ }^{95} \mathrm{Nb}$, and $830-1200 \mathrm{keV}$ for ${ }^{46} \mathrm{Sc}$. The overlap of activity from high-energy isotopes into lowenergy windows was corrected by differential spectroscopy (9). Flows are expressed in $\mathrm{mL} / \mathrm{min} / 100 \mathrm{~g}$ tissue by normalizing for tissue weight. Cerebral $\mathrm{O}_{2}$ uptake was calculated as: $\mathrm{CMRO}_{2}=$ forebrain blood flow $\times$ (arterial - sagittal venous $\mathrm{O}_{2}$ content). CVR was calculated as: (MABP - ICP)/forebrain blood flow at each $\mathrm{PaCO}_{2}$ value before ischemia and during reperfusion.

Electrical function. Our methods for monitoring electrical function in piglets have been previously described (2). Briefly, for SEP stimulating needle electrodes were placed percutaneously in the volar surface of the left foreleg in a location that caused a distal twitch. The intensity of the stimulus was $5.9 \mathrm{~mA}$, which was approximately twice motor threshold. The needles were secured, and a needle electrode secured to the animal's tongue acted as the ground.

The SEP was developed using a four-channel signal averager (Nicolet CA-1000. Nicolet Insruments Corp., Madison, WI). The stimulus duration of $200 \mu \mathrm{s}$ was used. Two hundred fifty-six stimuli were delivered at a rate of $5.9 / \mathrm{s}$ and averaged. Upper and lower band-pass filters were 30 and $1500 \mathrm{~Hz}$, respectively. At each measurement time, replicate waves were generated to ensure stability of the wave form. High-amplitude electrical artifact was automatically rejected by the computer. The peripheral nerve was stimulated only for the purpose of data collection (approximately $45 \mathrm{~s}$ each).

The active electrode and reference system yields a consistent wave form in the piglet. The wave form measured by the cervical electrode (C2) allows confirmation of electrical transit from the peripheral nerve through the spinal cord. The cortical wave form complex consists of a small positive wave (P1) followed by a large negative wave (N1) and a large positive wave (P2). The amplitude and latency of the wave form were evaluated using the cursor mode of the computer. The latency of $\mathrm{C} 2$ and $\mathrm{N} 1$ and the amplitude of the initial complex $\left(\mathrm{P}_{1} \mathrm{~N}_{1}\right)$ were measured and recorded for each data collection time point. Because of variability in baseline amplitudes and latencies between animals, these variables are expressed as percent of preischemic values.

For measurement of left hemispheric EEG, silver ball electrodes with shielded cables were placed in depressions in left frontal and parietal bone. EEG was used to document ischemia during aortic ligation. In each animal, the time to obtain a flat EEG during ischemia was noted. Recovery of EEG activity during reperfusion was not measured.

Plasma SOD activity. Arterial blood was collected in a test tube containing EDTA and centrifuged $(500 \times g$ for $20 \mathrm{~min})$. Plasma was then frozen at $-70^{\circ} \mathrm{C}$ until the enzyme assay was performed. SOD activity was assayed by its ability to inhibit xanthine oxidase-mediated cytochrome $c$ reduction $(10)$. Units of activity are defined as originally assigned by McCord and Fridovich (11).

Protocol. The study was divided into two parts that were completed concurrently: time control $(n=15)$ and ischemia ( $n$ $=24$ ). For both protocols, the investigators were blinded to individual animal treatment until the entire study was completed and all measurements were calculated. Each piglet received two ireatments of $3-\mathrm{mL}$ i.v. injections of either saline, vehicle, or drug as described below.

The first treatment administration was $30 \mathrm{~min}$ after completing surgical preparation and obtaining baseline values for SEP. Thirty min later, measurements of SEP were repeated and CBF responses to changes in $\mathrm{PaCO}_{2}$ were measured. The blood flow response to $\mathrm{CO}_{2}$ was accomplished by exposing each animal to one of three $\mathrm{PaCO}_{2}$ values (approximately 3.3, 5.3, and $8.7 \mathrm{kPa}$ ) in random sequence. $\mathrm{PaCO}_{2}$ was altered at the desired time by adjusting inspired $\mathrm{CO}_{2}$ concentration without altering minute ventilation. Approximately $5 \mathrm{~min}$ after reaching each desired $\mathrm{PaCO}_{2}$, measurements of physiologic variables, $\mathrm{CBF}$, and $\mathrm{CMRO}_{2}$ were made. At this point, we found steady state values for ICP. We have also found previously that, in dogs, the CBF response is greater than $90 \%$ of steady state after 5 min of steady state conditions in $\mathrm{CO}_{2}(12)$. After the sequence was completed. $\mathrm{PaCO}_{2}$ was returned to $40 \mathrm{~mm} \mathrm{Hg}$ and SEP measurements repeated.

The second treatment administration was at the end of ischemia in experimental groups and $15 \mathrm{~min}$ after return to normocapnia in time control groups. SEP was recorded during ischemia until isoelectric and at $5,10,15,30,45,60,75,90,105$, and 120 min after the second injection. In both groups, the CBF response to changes in $\mathrm{PaCO}_{2}$ was retested $2 \mathrm{~h}$ after the second treatment. For any particular animal, the sequence for $\mathrm{CO}_{2}$ reactivity was the same during both trial periods.

Drug treatments. In the time control protocol, three treatment 
combinations were studied to establish whether drug treatment had any effect on physiologic variables or CBF. The following time control groups were studied: SAL/SAL, saline first and second injection $(n=5)$; PEG/PEG, $10 \%$ by weight solution of PEG (molecular weight $=3350)$ in PBS $(\mathrm{pH}=7.4)$ first and second injection ( $n=5)$; PEG/PEG-SOD, first injection PEG and second injection PEG-SOD (30 $000 \mathrm{U}$; Sigma Chemical Co., St. Louis, MO) $(n=5)$. In the ischemia protocol, three treatment combinations were studied: PEG/PEG, PEG for first and second injection $(n=8)$; PEG-SOD/PEG, PEG-SOD (30 $000 \mathrm{U}$, i.v.) for first injection and PEG for second injection $(n=8)$; $\mathrm{PEG} /$ PEG-SOD, first injection PEG and second injection PEG-SOD $(30000 \mathrm{U})(n=8)$

Ischemia. Cerebral ischemia was induced by tightening ligatures that were previously placed around the inferior vena cava and ascending aorta. The time of ischemia was begun from the time of aortic occlusion. Preliminary experiments with radiolabeled microspheres have documented complete cessation of blood flow at the time of proximal aortic occlusion. To document complete aortic occlusion, blood pressure in the right axillary and left femoral arteries were recorded simultaneously. All animals demonstrated complete and immediate cessation of blood pressure at both sites after ligation of the ascending aorta. During ischemia, inspired $\mathrm{O}_{2}$ concentration was changed to $100 \%$, inspired $\mathrm{CO}_{2}$ concentration was changed to achieve an end-tidal $\mathrm{CO}_{2}$ of approximately $35 \mathrm{~mm} \mathrm{Hg}$, and blood was vented from the left atrial appendage (maintaining left atrial pressure between 12 and $20 \mathrm{~mm} \mathrm{Hg}$ ) to prevent the heart from decompensating from the high afterload produced by aortic occlusion. After 9.5 min of ischemia, the ligature around the inferior vena cava was removed. At $10 \mathrm{~min}$ of ischemia, reperfusion was induced by removing the ligature around the ascending aorta. At the onset of reperfusion, sodium bicarbonate $(1 \mathrm{mEq} / \mathrm{kg}$, i.v.) was given to treat systemic metabolic acidosis, which results from total body ischemia. The inspired $\mathrm{O}_{2}$ concentration was immediately decreased to maintain $\mathrm{PaO}_{2}$ between 100 and $175 \mathrm{~mm} \mathrm{Hg}(13.3$ and $23.3 \mathrm{kPa}$ ). Blood pressure was supported at preischemic values by i.v. administration of $0.9 \% \mathrm{NaCl}(10-15 \mathrm{~mL} / \mathrm{kg} / \mathrm{h})$ and epinephrine (1-5 $\mu \mathrm{g} / \mathrm{kg} / \mathrm{min})$. There was no difference between groups in the amount of saline or epinephrine needed to support blood pressure.

Data analysis. Each variable is expressed as mean and SEM. Paired $t$ tests were used to determine whether CVR and regional CBF changed with hypo- and hypercapnia and pre- and postischemic values. The Wilcoxon test was used when variance between groups was not similar. Two-way analysis of variance was used to evaluate the effect of treatment on recovery of SEP amplitude. Plasma SOD activity at the end of the protocol was compared by the Wilcoxon test. Statistical significance was assumed when $p$ was $\leq 0.05$.

\section{RESULTS}

Time control protocol. Physiologic parameters after the first and second injections are shown in Table 1. There were no physiologically significant differences between groups after the first or second injection or within any group over time. Arterial blood glucose concentration was maintained between 4.2 and $6.7 \mathrm{mmol} / \mathrm{L}$ and $\mathrm{Hb}$ concentration remained above $95 \mathrm{~g} / \mathrm{L}$ in all groups. At the end of the protocol, plasma SOD activity was $158000 \pm 11000 \mathrm{U} / \mathrm{L}$ in piglets treated with PEG-SOD, but was below the level of our detection $(<5000 \mathrm{U} / \mathrm{L})$ in both groups not given PEG-SOD.

Blood flow to forebrain and hindbrain and CVR for timecontrol piglets are shown in Table 2. There were no differences in blood flow or CVR between piglets treated with PEG or PEGSOD and piglets treated with saline at any time during the protocol. The only consistent change over time in each group was an increase in flow to forebrain and hindbrain and a decrease in CVR. In the SAL/SAL group, hypercapnic blood flow to hindbrain was greater after the second injection without an effect on CVR. In the PEG/PEG group, normocapnic blood flow to hindbrain was higher after the second injection without an effect on CVR. In the PEG/PEG-SOD group, normocapnic blood flow to forebrain was higher after the second injection without an effect on CVR. At normocapnia, $\mathrm{CMRO}_{2}$ was not changed over time in the SAL/SAL group $(3.0 \pm 0.1$ versus $2.7 \pm 0.3 \mathrm{~mL} /$ $\mathrm{min} / 100 \mathrm{~g})$ or the PEG/PEG group $(3.4 \pm 0.3$ versus $3.5 \pm 0.6$ $\mathrm{mL} / \mathrm{min} / 100 \mathrm{~g}$ ). However, $\mathrm{CMRO}_{2}$ was increased over time in piglets treated with $\mathrm{PEG} / \mathrm{PEG}-\mathrm{SOD}(2.9 \pm 0.3$ versus $3.3 \pm 0.2$ $\mathrm{mL} / \mathrm{min} / 100 \mathrm{~g}$ ).

Before the first drug injection, SEP $\mathrm{P}_{1} \mathrm{~N}_{1}$ amplitude (SAL/ SAL, $10.8 \pm 1.4 \mu \mathrm{V} ; \mathrm{PEG} / \mathrm{PEG}, 14.8 \pm 2.7 \mu \mathrm{V} ; \mathrm{PEG} / \mathrm{PEG}-\mathrm{SOD}$, $14.8 \pm 3.7 \mu \mathrm{V}$ ) was not different between groups. By $2 \mathrm{~h}$ after the second injection, SEP $P_{1} N_{1}$ amplitude was $97 \pm 3 \%$ of control in SAL/SAL, $83 \pm 12 \%$ of control in PEG/PEG, and $86 \pm 15 \%$ of control PEG/PEG-SOD.

Ischemia and reperfusion protocol. Physiologic parameters before ischemia and during reperfusion are shown in Table 3. There were no differences in these variables between groups before or after ischemia. Similarly, within each group there were no differences between values obtained before or after ischemia. At the onset of reperfusion, a large surge of blood pressure was prevented (Fig. 1) by being careful not to administer excessive epinephrine or normal saline. Arterial blood glucose concentration during normocapnia was increased at $2 \mathrm{~h}$ of reperfusion in piglets treated with PEG/PEG $(4.3 \pm 0.2$ versus $7.3 \pm 0.9 \mathrm{mmol} /$ $\mathrm{L})$ and PEG/PEG-SOD (4.2 \pm 0.3 versus $5.3 \pm 0.4 \mathrm{mmol} / \mathrm{L})$ but not in piglets treated with PEG-SOD/PEG $(5.8 \pm 1.0$ versus 4.4 $\pm 0.3 \mathrm{mmol} / \mathrm{L}$ ). Hb concentration remained above $95 \mathrm{~g} / \mathrm{L}$ in all groups throughout the protocol. Plasma SOD activity at the end of the experimental protocol averaged below our limits of detection in piglets treated with PEG/PEG and was elevated in both groups receiving PEG-SOD before ischemia (104000 \pm 7000 $\mathrm{U} / \mathrm{L})$ and at the time of reperfusion $(148000 \pm 14000 \mathrm{U} / \mathrm{L})$.

Before ischemia, in all groups, hypercapnia caused an increase in blood flow to forebrain and hypocapnia caused a decrease in blood flow to forebrain (Fig. 2). At $2 \mathrm{~h}$ of reperfusion, normocapnic forebrain blood flow was similar to preischemic normocapnic levels in all groups. During reperfusion, hypercapnic blood flow to forebrain was reduced compared with preischemic values in PEG/PEG piglets but not in either group treated with PEG-SOD (Fig. 2). The response observed in other regions within forebrain was similar to that in forebrain as a whole (e.g. hippocampus hypercapnic blood flow: PEG/PEG preischemic $64 \pm$ 10 , postischemic $48 \pm 6 \mathrm{~mL} / \mathrm{min} / 100 \mathrm{~g}, p<0.05$; PEG/PEGSOD preischemic $68 \pm 10$, postischemic $70 \pm 15 \mathrm{~mL} / \mathrm{min} / 100$ g, NS; PEG-SOD/PEG, preischemic $54 \pm 4$, postischemic $50 \pm$ $4 \mathrm{~mL} / \mathrm{min} / 100 \mathrm{~g}$, NS) except caudate nucleus. In caudate nucleus, hypercapnic blood flow was reduced after ischemia in PEG/PEG-treated piglets (preischemic $105 \pm 14$, postischemic $62 \pm 9 \mathrm{~mL} / \mathrm{min} / 100 \mathrm{~g}, p<0.05$ ). Treatment with PEG-SOD at reperfusion (preischemic $104 \pm 15$, postischemic $106 \pm 28 \mathrm{~mL}$ / $\mathrm{min} / 100 \mathrm{~g}$ ), but not before ischemia (preischemic $88 \pm 10$, postischemic $62 \pm 7 \mathrm{~mL} / \mathrm{min} / 100 \mathrm{~g}, p<0.05$ ) prevented this decrease. Postischemic hypocapnic blood flow was not different from preischemic hypocapnic values in any group (Fig. 2).

There was no difference between experimental groups in blood flow to hindbrain (i.e. PEG-SOD/PEG or PEG/PEG-SOD versus $\mathrm{PEG} / \mathrm{PEG}$ ) at any $\mathrm{PaCO}_{2}$ value before ischemia (Fig. 3). At $2 \mathrm{~h}$ of reperfusion, hindbrain blood flow at normocapnia was greater than preischemic values in PEG control piglets and in piglets treated with PEG-SOD at reperfusion. During hypocapnia, hindbrain blood flow was greater after ischemia than before ischemia in all groups. However, there was no difference between pre- and postischemic values of hindbrain blood flow during hypercapnia in any group (Fig. 3). The response observed in other regions within hindbrain was similar to hindbrain as a whole (e.g. cerebellum hypercapnic; $P E G / P E G$, preischemic $109 \pm 18$, postischemic $124 \pm 14 \mathrm{~mL} / \mathrm{min} / 100 \mathrm{~g}$, NS; PEG/PEG-SOD, preis- 
PEG-SOD AND POST-ISCHEMIC CBF $\mathrm{CO}_{2}$ RESPONSE

Table 1. Arterial blood gases and CPP in time control piglets*

\begin{tabular}{|c|c|c|c|c|c|c|}
\hline & \multicolumn{3}{|c|}{ After first drug injection } & \multicolumn{3}{|c|}{ After second drug injection } \\
\hline & Hypocapnia & Normocapnia & Hypercapnia & Hypocapnia & Normocapnia & Hypercapnia \\
\hline \multicolumn{7}{|l|}{$\mathrm{pH}$} \\
\hline SAL/SAL & $7.56 \pm 0.03$ & $7.38 \pm 0.01$ & $7.21 \pm 0.02$ & $7.53 \pm 0.02$ & $7.34 \pm 0.01 \dagger$ & $7.20 \pm 0.02$ \\
\hline $\mathrm{PEG} / \mathrm{PEG}$ & $7.53 \pm 0.03$ & $7.39 \pm 0.01$ & $7.22 \pm 0.02$ & $7.56 \pm 0.03$ & $7.41 \pm 0.03$ & $7.23 \pm 0.02$ \\
\hline PEG/PEG-SOD & $7.53 \pm 0.03$ & $7.38 \pm 0.02$ & $7.20 \pm 0.04$ & $7.51 \pm 0.02$ & $7.36 \pm 0.01$ & $7.21 \pm 0.03$ \\
\hline \multicolumn{7}{|l|}{$\mathrm{PaCO}_{2}(\mathrm{kPa})$} \\
\hline SAL/SAL & $3.4 \pm 0.1$ & $5.5 \pm 0.2$ & $8.5 \pm 0.3$ & $3.5 \pm 0.1$ & $5.8 \pm 0.2$ & $8.9 \pm 0.6$ \\
\hline PEG/PEG & $3.6 \pm 0.2$ & $5.1 \pm 0.1$ & $8.3 \pm 0.2$ & $3.4 \pm 0.1$ & $5.1 \pm 0.3$ & $8.2 \pm 0.2$ \\
\hline PEG/PEG-SOD & $3.4 \pm 0.2$ & $5.3 \pm 0.2$ & $8.7 \pm 0.6$ & $3.7 \pm 0.1$ & $5.3 \pm 0.2$ & $8.4 \pm 0.3$ \\
\hline \multicolumn{7}{|l|}{$\mathrm{PaO}_{2}(\mathrm{kPa})$} \\
\hline SAL/SAL & $21.5 \pm 2.7$ & $19.2 \pm 2.5$ & $22.7 \pm 1.3$ & $20.1 \pm 2.6$ & $20.5 \pm 1.6$ & $20.9 \pm 1.9$ \\
\hline PEG/PEG & $22.9 \pm 3.2$ & $21.6 \pm 1.9$ & $21.2 \pm 2.0$ & $21.3 \pm 0.9$ & $21.3 \pm 1.6$ & $18.4 \pm 1.3$ \\
\hline PEG/PEG-SOD & $21.3 \pm 2.1$ & $19.5 \pm 1.7$ & $20.3 \pm 1.1$ & $17.9 \pm 1.6$ & $18.3 \pm 1.6$ & $18.4 \pm 1.3$ \\
\hline \multicolumn{7}{|l|}{$\mathrm{CPP}(\mathrm{mm} \mathrm{Hg})$} \\
\hline SAL/SAL & $80 \pm 4$ & $80 \pm 5$ & $76 \pm 6$ & $76 \pm 6$ & $82 \pm 3$ & $72 \pm 7$ \\
\hline PEG/PEG & $80 \pm 2$ & $77 \pm 3$ & $73 \pm 3$ & $76 \pm 5$ & $79 \pm 2$ & $78 \pm 1$ \\
\hline PEG/PEG-SOD & $85 \pm 5$ & $90 \pm 6$ & $84 \pm 3$ & $85 \pm 5$ & $85 \pm 5$ & $70 \pm 5 \dagger$ \\
\hline
\end{tabular}

* Values are mean \pm SEM. CPP, cerebral perfusion pressure. SAL/SAL, $3 \mathrm{~mL}$ of saline i.v. 30 min before first test of $\mathrm{CO}_{2}$ reactivity and $15 \mathrm{~min}$ after return to normocapnia; PEG/PEG. $3 \mathrm{~mL}$ of PEG i.v. $30 \mathrm{~min}$ before preischemic first test of $\mathrm{CO}_{2}$ reactivity and 15 min after return to normocapnia: PEG/PEG-SOD. $3 \mathrm{~mL}$ of $10 \%$ PEG i.v. $30 \mathrm{~min}$ before first test of $\mathrm{CO}_{2}$ reactivity and $3 \mathrm{~mL}$ of PEG-SOD (10 000 000 U/L) i.v. 15 $\min$ after return to normocapnia. $n=5$ for each group. There were no differences between values obtained in SAL/SAL group compared with other groups for any variable.

$+p \leq 0.05$ same experimental condition after first and second injection (e.g. PEG/PEG $\mathrm{PaCO}_{2}$ at normocapnia. after first and second injection).

Table 2. Forebrain and hindbrain blood flow and CVR in time control piglets exposed to hypocapnia. normocapnia. and hypercapnia after each injection*

\begin{tabular}{|c|c|c|c|c|c|c|}
\hline & \multicolumn{3}{|c|}{ After first injection } & \multicolumn{3}{|c|}{ After second injection } \\
\hline & Hypocapnia & Normocapnia & Hypercapnia & Hypocapnia & Normocapnia & Hypercapnia \\
\hline \multicolumn{7}{|c|}{ Forebrain $(\mathrm{mL} / \mathrm{min} / 100 \mathrm{~g})$} \\
\hline SAL/SAL & $28 \pm 2 \dagger$ & $39 \pm 3$ & $65 \pm 7 \dagger$ & $46 \pm 4 \dagger \ddagger$ & $57 \pm 6$ & $116 \pm 28 t$ \\
\hline PEG/PEG & $32 \pm 3 \dagger$ & $44 \pm 2$ & $92 \pm 13+$ & $45 \pm 4+\ddagger$ & $56 \pm 6$ & $105 \pm 14 \dagger$ \\
\hline PEG/PEG-SOD & $30 \pm 3 \dagger$ & $37 \pm 3$ & $109 \pm 41 \dagger$ & $39 \pm 4+\ddagger$ & $47 \pm 4 \ddagger$ & $99 \pm 15 \dagger$ \\
\hline \multicolumn{7}{|c|}{ Hindbrain blood flow $(\mathrm{mL} / \mathrm{min} / 100 \mathrm{~g})$} \\
\hline SAL/SAL & $34 \pm 2 \dagger$ & $57 \pm 2$ & $140 \pm 27 \dagger$ & $62 \pm 4 t \ddagger$ & $91 \pm 9$ & $220 \pm 38+\ddagger$ \\
\hline PEG/PEG & $35 \pm 4 \dagger$ & $55 \pm 3$ & $211 \pm 46 \dagger$ & $55 \pm 5+t$ & $80 \pm 8 \ddagger$ & $251 \pm 40 \dagger$ \\
\hline PEG/PEG-SOD & $35 \pm 4 \dagger$ & $51 \pm 6$ & $210 \pm 83 \dagger$ & $52 \pm 8+\ddagger$ & $71 \pm 10$ & $200 \pm 21 \dagger$ \\
\hline \multicolumn{7}{|c|}{$\mathrm{CVR}(\mathrm{mm} \mathrm{Hg} / \mathrm{mL} / \mathrm{min} / 100 \mathrm{~g})$} \\
\hline SAL/SAL & $2.9 \pm 0.3+$ & $2.1 \pm 0.2$ & $1.3 \pm 0.2 \dagger$ & $1.7 \pm 0.2 \ddagger$ & $1.5 \pm 0.2$ & $0.8 \pm 0.1 \dagger$ \\
\hline PEG/PEG & $2.5 \pm 0.2 \dagger$ & $1.8 \pm 0.2$ & $1.0 \pm 0.2 \dagger$ & $1.7 \pm 0.2 \ddagger$ & $1.5 \pm 0.2$ & $0.9 \pm 0.2 \dagger$ \\
\hline PEG/PEG-SOD & $2.8 \pm 0.2$ & $2.5 \pm 0.2$ & $1.3 \pm 0.4 \dagger$ & $2.2 \pm 0.2+\ddagger$ & $1.8 \pm 0.1$ & $0.8 \pm 0.2+$ \\
\hline
\end{tabular}

* Values are mean \pm SEM. SAL/SAL, $3 \mathrm{~mL}$ of saline i.v. 30 min before first test of $\mathrm{CO}_{2}$ reactivity and $15 \mathrm{~min}$ after return to normocapnia: $\mathrm{PEG} /$ PEG, $3 \mathrm{~mL}$ of PEG i.v. $30 \mathrm{~min}$ before preischemic first test of $\mathrm{CO}_{2}$ reactivity and $15 \mathrm{~min}$ after return to normocapnia: PEG/PEG-SOD, $3 \mathrm{~mL}$ of $10 \%$ PEG i.v. $30 \mathrm{~min}$ before first test of $\mathrm{CO}_{2}$ reactivity and $3 \mathrm{~mL}$ of PEG-SOD $(10000000 \mathrm{U} / \mathrm{L})$ i.v. $15 \mathrm{~min}$ after return to normocapnia. $n=5$ for each group.

$+p \leq 0.05$ vs corresponding normocapnia after first or second injection (e.g. PEG/PEG value for PaCO2 at first normocapnia $v s$ value at first hypercapnia).

$\ddagger p \leq 0.05$ vs value after first injection at same experimental condition (e.g. PEG/PEG CVR at normocapnia, after first and second injection).

chemic $106 \pm 16$, postischemic $152 \pm 27 \mathrm{~mL} / \mathrm{min} / 100 \mathrm{~g}, \mathrm{NS}$ PEG-SOD/PEG, preischemic $95 \pm 10$, postischemic $136 \pm 12$ $\mathrm{mL} / \mathrm{min} / 100 \mathrm{~g}, \mathrm{NS})$.

Before ischemia, CVR increased in response to hypocapnia and decreased in response to hypercapnia in all groups (Fig. 4). During reperfusion, there was no difference between pre- and postischemic CVR values during normocapnia and hypocapnia. During reperfusion, hypercapnic CVR remained higher than preischemic values in the PEG/PEG group but was similar to preischemic values in both groups treated with PEG-SOD (Fig. 4).

Postischemic $\mathrm{CMRO}_{2}$ was not different from preischemic values in piglets treated with PEG/PEG $(3.2 \pm 0.2$ versus $3.0 \pm 0.1$ $\mathrm{mL} / \mathrm{min} / 100 \mathrm{~g})$ or PEG-SOD/PEG (3.6 \pm 0.3 versus $3.0 \pm 0.2$ $\mathrm{mL} / \mathrm{min} / 100 \mathrm{~g}$ ) but was decreased in piglets treated with PEG/ PEG-SOD ( $3.7 \pm 0.2$ versus $2.6 \pm 0.3 \mathrm{~mL} / \mathrm{min} / 100 \mathrm{~g})$.

Before ischemia, there were no differences between groups in size of the $P_{1} N_{1}$ amplitude or $N_{1}$ latency (PEG/PEG: $14 \pm 4 \mu \mathrm{V}$, $27 \pm 1 \mathrm{~ms}$; PEG-SOD/PEG: $24 \pm 6 \mu \mathrm{V}, 27 \pm 1 \mathrm{~ms}$; PEG/PEGSOD: $22 \pm 3 \mu \mathrm{V}, 28 \pm 1 \mathrm{~ms})$. During ischemia, the EEG became isoelectric within $30 \mathrm{~s}$ and SEP became isoelectric within $90 \mathrm{~s}$ in all groups. During reperfusion, there was no difference in percent recovery of $P_{1} N_{1}$ amplitude (Fig. 5).

\section{DISCUSSION}

In time control piglets, PEG and PEG-SOD had no effect on CBF during normocapnia or hypercapnia. In SAL/SAL- and PEG/PEG-treated piglets, $\mathrm{CMRO}_{2}$ and SEP amplitude were not affected by time. Although $\mathrm{CMRO}_{2}$ was increased slightly in PEG/PEG-SOD-treated piglets exposed to the time control protocol, there was no effect of treatment on maintenance of cerebral electrical activity. After $10 \mathrm{~min}$ of ischemia, no group demonstrated delayed hypoperfusion at $2 \mathrm{~h}$ of reperfusion, but $\mathrm{CMRO}_{2}$ 
Table 3. Arterial blood gases and CPP before and after $2 \mathrm{~h}$ of transient global cerebral ischemia*

\begin{tabular}{|c|c|c|c|c|c|c|}
\hline & \multicolumn{3}{|c|}{ Preischemia } & \multicolumn{3}{|c|}{ Postischemia } \\
\hline & Hypocapnia & Normocapnia & Hypercapnia & Hypocapnia & Normocapnia & Hypercapnia \\
\hline \multicolumn{7}{|l|}{$\mathrm{pH}$} \\
\hline PEG/PEG & $7.48 \pm 0.02$ & $7.33 \pm 0.02$ & $7.18 \pm 0.02$ & $7.55 \pm 0.03$ & $7.39 \pm 0.04$ & $7.24 \pm 0.04$ \\
\hline PEG-SOD/PEG & $7.52 \pm 0.02$ & $7.35 \pm 0.02$ & $7.20 \pm 0.02$ & $7.47 \pm 0.04$ & $7.33 \pm 0.04$ & $7.19 \pm 0.03$ \\
\hline PEG/PEG-SOD & $7.52 \pm 0.02$ & $7.37 \pm 0.02$ & $7.18 \pm 0.01$ & $7.55 \pm 0.02$ & $7.40 \pm 0.01$ & $7.21 \pm 0.02$ \\
\hline \multicolumn{7}{|l|}{$\mathrm{PaCO}_{2}(\mathrm{kPa})$} \\
\hline PEG/PEG & $3.4 \pm 0.2$ & $5.2 \pm 0.2$ & $8.5 \pm 0.4$ & $3.4 \pm 0.1$ & $5.5 \pm 0.4$ & $8.5 \pm 0.6$ \\
\hline PEG-SOD/PEG & $3.3 \pm 0.1$ & $5.4 \pm 0.2$ & $8.3 \pm 0.4$ & $3.6 \pm 0.2$ & $5.7 \pm 0.3$ & $8.5 \pm 0.6$ \\
\hline PEG/PEG-SOD & $3.4 \pm 0.2$ & $4.7 \pm 0.2$ & $8.7 \pm 0.2$ & $3.5 \pm 0.1$ & $5.4 \pm 0.1$ & $8.9 \pm 0.4$ \\
\hline \multicolumn{7}{|l|}{$\mathrm{PaO}_{2}(\mathrm{kPa})$} \\
\hline PEG/PEG & $22.1 \pm 2.0$ & $20.1 \pm 1.7$ & $18.8 \pm 1.2$ & $22.1 \pm 3.2$ & $21.5 \pm 2.4$ & $19.9 \pm 2.1$ \\
\hline PEG-SOD/PEG & $21.6 \pm 0.9$ & $20.4 \pm 0.8$ & $20.5 \pm 0.9$ & $20.8 \pm 1.6$ & $21.3 \pm 1.7$ & $21.3 \pm 1.6$ \\
\hline PEG/PEG-SOD & $22.7 \pm 2.1$ & $20.5 \pm 1.6$ & $20.3 \pm 1.2$ & $20.7 \pm 2.3$ & $19.6 \pm 2.0$ & $21.2 \pm 1.3$ \\
\hline \multicolumn{7}{|l|}{$\mathrm{CPP}(\mathrm{mm} \mathrm{Hg})$} \\
\hline PEG/PEG & $78 \pm 3$ & $83 \pm 4$ & $67 \pm 5$ & $81 \pm 3$ & $76 \pm 5$ & $75 \pm 3$ \\
\hline PEG-SOD/PEG & $85 \pm 4$ & $88 \pm 4$ & $74 \pm 2$ & $82 \pm 4$ & $83 \pm 3$ & $79 \pm 3$ \\
\hline PEG/PEG-SOD & $81 \pm 3$ & $82 \pm 4$ & $73 \pm 5$ & $84 \pm 5$ & $87 \pm 5$ & $79 \pm 4$ \\
\hline
\end{tabular}

* Values are mean \pm SEM. CPP, cerebral perfusion pressure. PEG/PEG. $3 \mathrm{~mL}$ of $10 \%$ PEG i.v. before preischemic test of $\mathrm{CO}_{2}$ reactivity and at reperfusion; PEG-SOD/PEG, $3 \mathrm{~mL}$ of PEG-SOD $(10000000 \mathrm{U} / \mathrm{L})$ i.v. before preischemic test of $\mathrm{CO}_{2}$ reactivity and $3 \mathrm{~mL}$ of $\mathrm{PEG}$ i.v. at reperfusion; PEG/PEG-SOD, $3 \mathrm{~mL}$ of PEG i.v. before preischemic test of $\mathrm{CO}_{2}$ reactivity and $3 \mathrm{~mL}$ of PEG-SOD $(10000000 \mathrm{U} / \mathrm{L})$ i.v. at reperfusion. $n=8$ for each group. There was also no difference within a group between values obtained before or after ischemia during any individual experimental condition.

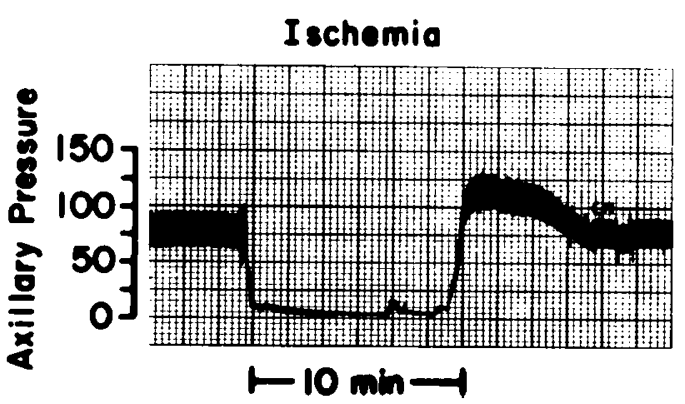

Fig. 1. Representative arterial blood pressure $(\mathrm{mm} \mathrm{Hg})$ recording from a piglet exposed to ischemia (axillary blood pressure near zero) and reperfusion.

was depressed in piglets treated with PEG/PEG-SOD. Recovery of SEP amplitude was incomplete and not different between groups. Hypercapnic blood flow was reduced in PEG/PEGtreated piglets but not in either group given PEG-SOD. We conclude that scavenging oxygen radicals with PEG-SOD alters recovery of $\mathrm{CBF}$ response to hypercapnia via a mechanism that does not involve improved cerebral function (e.g. SEP amplitude, $\mathrm{CMRO}_{2}$ ).

In absence of ischemia, others have demonstrated in newborn piglets (13) that topical application of SOD and catalase via a cranial window preparation appeared to augment vasodilation to elevated $\mathrm{CO}_{2}$. In control animals, arteriolar diameter increased from 26 to $33 \%$ compared with an increase of $53 \%$ in arterioles exposed to SOD and catalase. These authors proposed that exposure to $\mathrm{CO}_{2}$ results in production of oxygen radicals during conversion of prostaglandin $\mathrm{G}_{2}$ to prostaglandin $\mathrm{H}_{2}$. Once oxygen radicals are produced, they can inhibit prostaglandin cyclooxygenase (14) and limit further production of vasodilator prostanoids. In the presence of SOD and catalase, greater release of vasodilator prostanoids would be predicted during hypercapnia because of increased activity of cyclooxygenase. The finding of no accentuation of hypercapnic CBF with PEG-SOD before ischemia in our study may be due to the need for catalase, which we did not administer, the slightly younger age of the piglets used in the previous study, differences in anesthetic management, or limited access of PEG-SOD into vascular endothelium during the course of the time control experiments (15).
During reperfusion from ischemia, we (3) and others (4) have demonstrated impaired hypercapnic reactivity. After ischemia and reperfusion, in piglets, the major deficit appears to be the lack of increased production of vasodilator prostanoids to hypercapnia rather than impaired vascular response to prostanoids that are applied locally (4). Our finding of preserved CBF response to hypercapnia after ischemia in piglets receiving PEGSOD is consistent with the hypothesis that oxygen radicals produced during ischemia and reperfusion $(8,16)$ can lead to inhibition of cyclooxygenase activity with decreased postischemic production of vasodilator prostanoids. This finding implies that oxygen radical injury in brain occurs during reperfusion and that PEG-SOD is able to at least partially access one site of oxygen radical production that affects vascular smooth muscle during ischemia and reperfusion. In our experimental paradigm, $100 \% \mathrm{O}_{2}$ was administered during ischemia, a time when there was no CBF and therefore little chance for increased radical production in an oxygen-enriched environment $(17,18)$. Immediately upon reperfusion, inspired oxygen was decreased to maintain normoxia throughout reperfusion.

Oxygen radicals appear to have a predilection for production of vascular injury in brain. For example, application of oxygen radical-generating systems via a cranial window results in vascular paralysis and endothelial injury (19) and altered reactivity to hypercapnia (20). Similarly, enzymatically generated oxygen radicals alter endothelial and blood-brain barrier permeability and elicit brain edema (21). In gerbils, i.v. administration of high-dose recombinant human SOD (bolus, $100000 \mathrm{U} / \mathrm{kg}$; infusion $800000 \mathrm{U} / \mathrm{kg} / \mathrm{h}$ ) starting $10 \mathrm{~min}$ before $1 \mathrm{~h}$ of bilateral carotid occlusion resulted in attenuated vasogenic edema at $3 \mathrm{~h}$ of reperfusion (22), supporting the contention that the vasculature is an important site of oxygen radical injury.

In rat, cerebral hyperemia during hypercapnia appears to be mediated via a pathway that involves nitric oxide or nitric oxidecontaining compound (23). In in vitro studies, superoxide anion has been demonstrated to inactivate endothelium-derived relaxing factor (nitric oxide) (24). If these same mechanisms are operative in piglets, our data would suggest that impaired hypercapnic response during reperfusion is due to inactivation of nitric oxide produced during hypercapnia by superoxide anion produced during reperfusion from ischemia.

Compared with SOD, PEG-SOD is known to have more rapid entrance into endothelial cells in vitro (15). However, even in 


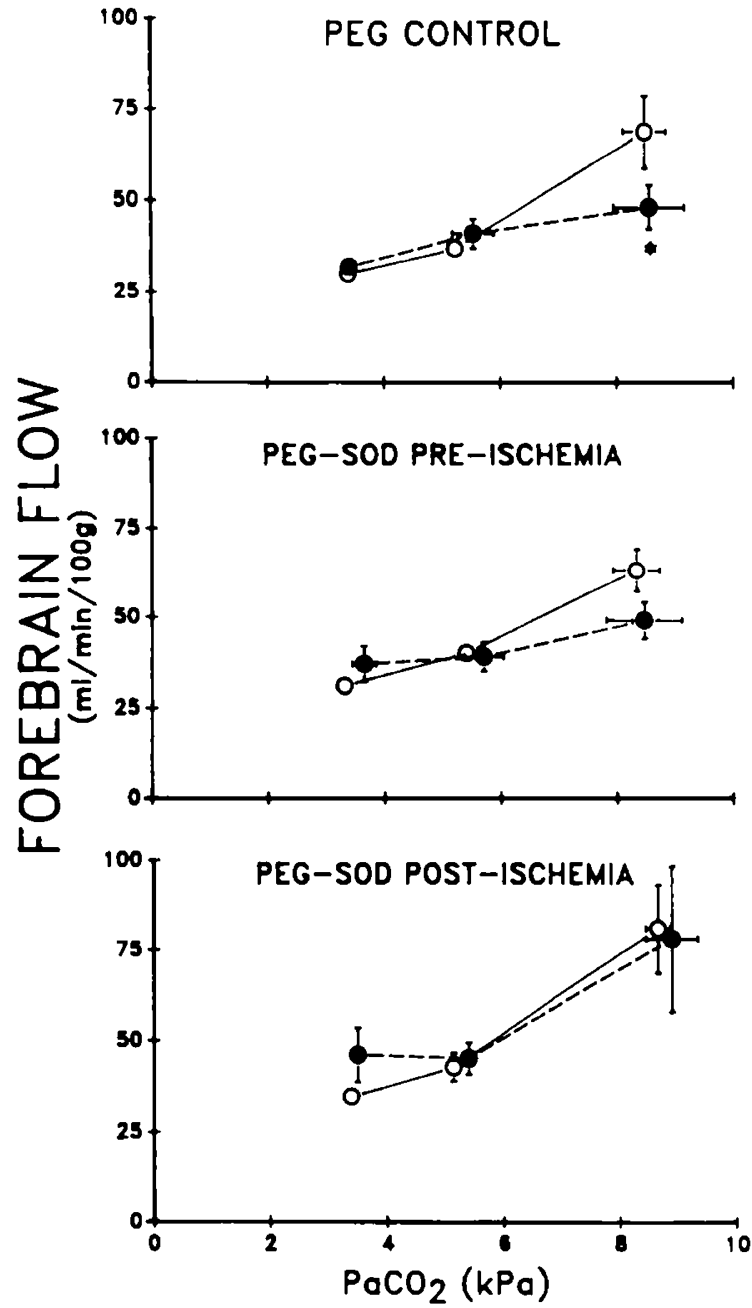

Fig. 2. Blood flow to forebrain before ischemia (open circles) and at ? h of reperfusion (filled circles) in piglets during hypocapnia, normosapnia, and hypercapnia. Values are mean and SEM for flow and $\mathrm{PaCO}_{2}$. Piglets treated with PEG/PEG ( $3 \mathrm{~mL}$ of $10 \%$ PEG i.v. before preischemic est of $\mathrm{CO}_{2}$ reactivity and at reperfusion) are demonstrated in the $t o p$ anel; piglets treated with PEG-SOD/PEG (30000 U of PEG-SOD i.v. efore preischemic test of $\mathrm{CO}_{2}$ reactivity and $3 \mathrm{~mL}$ of PEG i.v. at eperfusion) are demonstrated in the middle panel; piglets treated with गEG/PEG-SOD $\left(3 \mathrm{~mL}\right.$ of PEG i.v. before preischemic test of $\mathrm{CO}_{2}$ eactivity and $30000 \mathrm{U}$ of PEG-SOD i.v. at reperfusion) are demonitrated in the bottom panel. $n=8$ for each group. ${ }^{*}, p \leq 0.05$ vs reischemic value at corresponding $\mathrm{PaCO}_{2}$.

he in vitro system, because PEG-SOD appears to be taken up Jy endothelial cells by pinocytosis, it was not until $4 \mathrm{~h}$ of exposure .o very high concentrations of PEG-SOD that increased SOD Ictivity was apparent. In piglets, i.v. administration of PEG-SOD loes not appear to cause an increase in parenchymal SOD ictivity even in the setting of ischemia and reperfusion (25). These data in combination with the finding of improved recovery of CBF response to hypercapnia without improved recovery of slectrical function suggest that in this study the site of action of ?EG-SOD is in the vascular compartment. For example, SOD nay act to prevent oxygen radical injury to cerebral arterioles 19), prevent superoxide anion-induced platelet adhesion (26), or prevent superoxide-mediated leukocyte-endothelial cell adrerence (27).

In cats, topical application of SOD and catalase (cranial winlow preparation) before ischemia results in a preserved vascular esponse to acetylcholine and hypocapnia and minimized bloodsrain barrier permeability changes during reperfusion (8). In this itudy $(8)$, preserved vasodilator response to topical acetylcholine

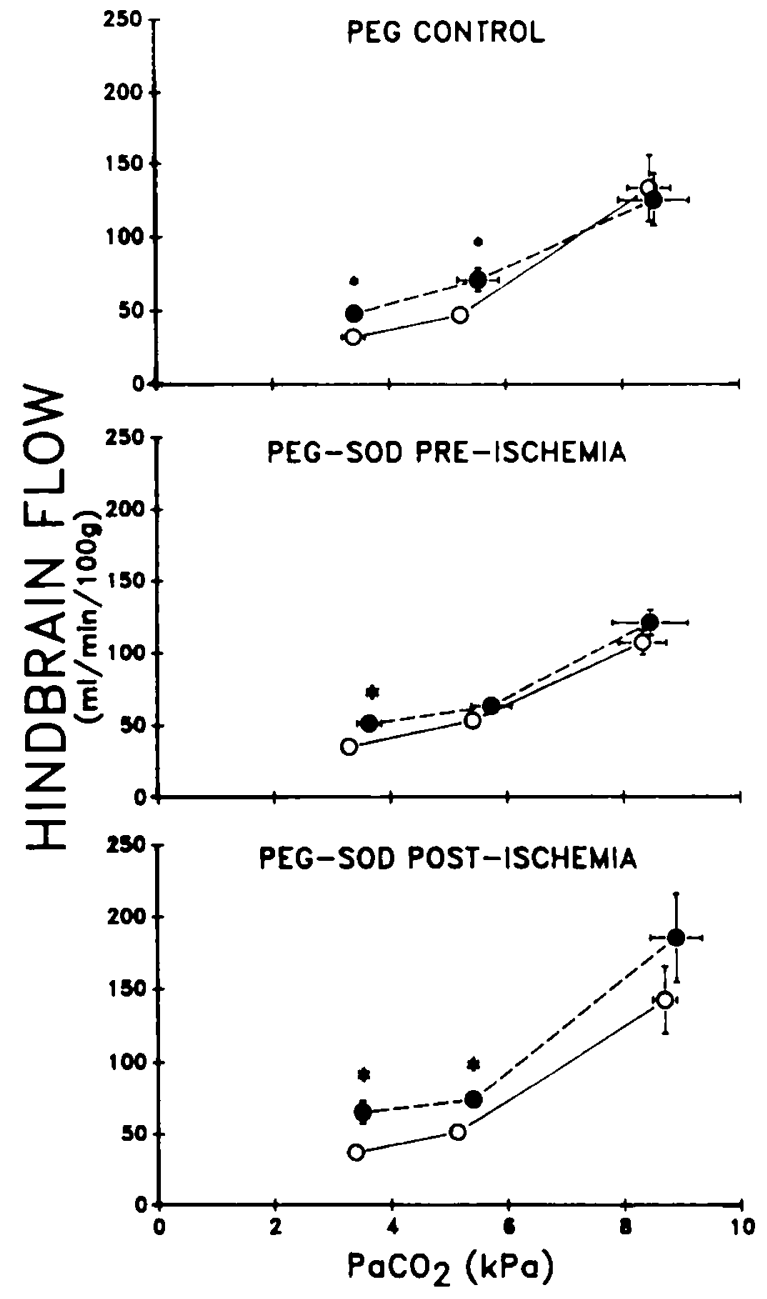

Fig. 3. Blood flow to hindbrain before ischemia (open circles) and at $2 \mathrm{~h}$ of reperfusion (filled circles) in piglets during hypocapnia. normocapnia, and hypercapnia. Values are mean and SEM for flow and $\mathrm{PaCO}_{2}$ Piglets treated with PEG/PEG ( $3 \mathrm{~mL}$ of $10 \%$ PEG i.v. before preischemic test of $\mathrm{CO}_{2}$ reactivity and at reperfusion) are demonstrated in the $t o p$ panel; piglets treated with PEG-SOD/PEG ( $30000 \mathrm{U}$ of PEG-SOD i.v. before preischemic test of $\mathrm{CO}_{2}$ reactivity and $3 \mathrm{~mL}$ of $P E G$ i.v. at reperfusion) are demonstrated in the middle panel; piglets treated with PEG/PEG-SOD ( $3 \mathrm{~mL}$ of PEG i.v. before preischemic test of $\mathrm{CO}_{2}$ reactivity and $30000 \mathrm{U}$ of PEG-SOD i.v. at reperfusion) are demonstrated in the bottom panel. $n=8$ for each group. ${ }^{*}, p \leq 0.05$ is preischemic value at corresponding $\mathrm{PaCO}_{2}$.

during reperfusion from ischemia, even with more selective cerebral ischemia and topical application of oxygen radical scavengers, is consistent with our finding of preserved postischemic vasodilator response after administration of PEG-SOD. Similarly, administration of oxygen radical scavengers can prevent postischemic injury to blood-brain barrier (8). In preliminary experiments, Leffler et al. (28) demonstrated no recovery of pial vascular response to hypercapnia during reperfusion after administration of oxygen radical scavengers. One potential explanation for the difference in results is that in our study and that of Nelson et al. (8) ischemia was produced by vascular occlusion, whereas in the study by Leffler et al. (28) ischemia was produced by elevation of ICP, which may have resulted in a different type of vascular injury. Indeed, we have demonstrated (29) that an inhibitor of lipid peroxidation lacks efficacy in a model of elevated ICP, whereas efficacy is apparent in a model of cardiac arrest (30), suggesting additional injury produced by models using increased ICP to produce complete ischemia.

PEG-SOD did not alter CBF during hypocapnia in the present 


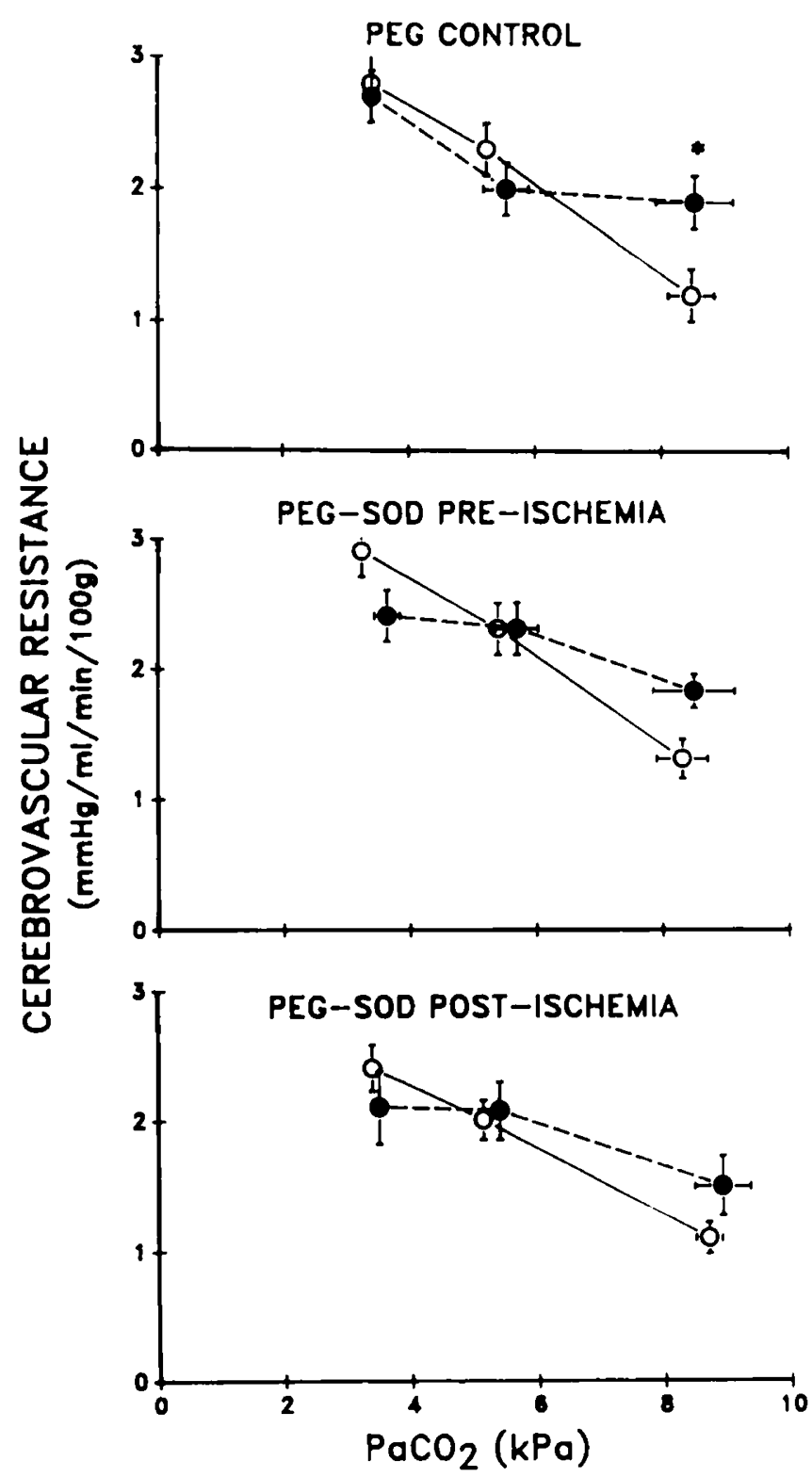

Fig. 4. Cerebrovascular resistance before ischemia (open circles) and at $2 \mathrm{~h}$ of reperfusion (filled circles) in piglets during hypocapnia, normocapnia, and hypercapnia. Values are mean and SEM for cerebrovascular resistance and $\mathrm{PaCO}_{2}$. Piglets treated with PEG/PEG ( $3 \mathrm{~mL}$ of $10 \%$ $P E G$ i.v. before preischemic test of $\mathrm{CO}_{2}$ reactivity and at reperfusion) are demonstrated in the top panel; piglets treated with PEG-SOD/PEG (30 $000 \mathrm{U}$ of PEG-SOD i.v. before preischemic test of $\mathrm{CO}_{2}$ reactivity and $3 \mathrm{~mL}$ of PEG i.v. at reperfusion) are demonstrated in the middle panel; piglets treated with PEG/PEG-SOD ( $3 \mathrm{~mL}$ of PEG i.v. before preischemic test of $\mathrm{CO}_{2}$ reactivity and $30000 \mathrm{U}$ of PEG-SOD i.v. at reperfusion) are demonstrated in the bottom panel. $n=8$ for each group. ${ }^{*}, p \leq 0.05 \mathrm{vs}$ preischemic value at corresponding $\mathrm{PaCO}_{2}$.

study. This may be explained by the finding that there was no difference in CBF during hypocapnia at $2 \mathrm{~h}$ of reperfusion in control animals in this and a previous study (3).

As previously demonstrated in piglets (2), we found no evidence of postischemic delayed hypoperfusion in this study (e.g. no difference in blood flow to forebrain during normocapnia preischemia versus postischemia). We were therefore unable to directly test the effect of PEG-SOD on postischemic hypoperfusion. During resuscitation from asphyxia, treatment with PEGSOD in combination with PEG-conjugated catalase is associated with increased hyperemia and improved recovery of $\mathrm{CBF}$ and $\mathrm{CMRO}_{2}$ in newborn lambs (31). However, after global ischemia,

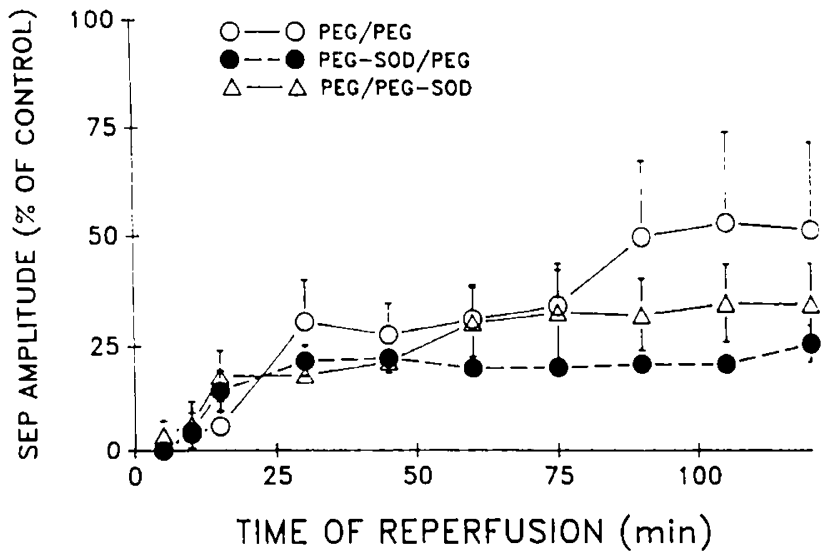

Fig. 5. Amplitude of the SEP wave during reperfusion from ischemia. Piglets treated with PEG/PEG ( $3 \mathrm{~mL}$ of $10 \%$ PEG i.v. before preischemic test of $\mathrm{CO}_{2}$ reactivity and at reperfusion) are demonstrated by the open circles; piglets treated with PEG-SOD/PEG (30 $000 \mathrm{U}$ of PEG-SOD i.v. before preischemic test of $\mathrm{CO}_{2}$ reactivity and $3 \mathrm{~mL}$ of $P E G$ i.v. at reperfusion) are demonstrated by the filled circles; piglets treated with PEG/PEG-SOD ( $3 \mathrm{~mL}$ of PEG i.v. before preischemic test of $\mathrm{CO}_{2}$ reactivity and $30000 \mathrm{U}$ of PEG-SOD i.v. at reperfusion) are demonstrated by the triangles. $n=8$ for each group.

i.v. PEG-SOD administration has no effect on postischemic hyperemia in piglets (32) and SOD has no effect on postischemic hypoperfusion in rat (33). We believe that the explanation for these different findings is that the mechanism for postischemic hyperemia and delayed hypoperfusion are different after asphyxia without sustained cessation of CBF. However, it is also possible that catalase, which we did not administer, is necessary to produce any beneficial effect on these parameters.

The apparent (but not statistically significant) greater effect of treatment with PEG-SOD just before reperfusion, compared with pretreatment, may be due to a greater activity of SOD in plasma after bolus administration. This may also account for differences in pretreatment and posttreatment of PEG-SOD in caudate nucleus. Because hemorrhage was used in all groups during ischemia to decrease cardiac preload, the activity of SOD per $\mathrm{mL}$ of blood available for scavenging at the time of reperfusion would be anticipated to be greater in the group given SOD when the blood volume was at its lowest (PEG/PEG-SOD). We did not anticipate this and therefore only measured plasma SOD activity at the end of reperfusion when blood volume would be expected to be similar between groups. The finding of a positive effect of PEG-SOD on CBF response to hypercapnia without PEG-catalase is consistent with the hypothesis that, even though superoxide is not as reactive as other radical species, it is still capable of producing significant abnormalities. Other studies that show benefit for SOD, administered by itself, with transient (34) and permanent focal ischemia (35) and head trauma (36) support this hypothesis. In addition, the beneficial effect afforded by postischemic administration of PEG-SOD supports the hypothesis of oxygen radical production with vascular abnormalities during reperfusion.

In summary, our data demonstrate that oxygen radicals contribute to impaired hypercapnic CBF after transient ischemia in piglets. Administration of PEG-SOD at the time of reperfusion can ameliorate altered hypercapnic CBF via a mechanism that does not involve improved cerebral function (e.g. SEP amplitude, $\mathrm{CMRO}_{2}$ ). Although our study did not specifically evaluate prostanoid or nitric oxide mechanisms, in combination with data from the literature, our data suggest that oxygen radicals produced during ischemia and reperfusion act to inhibit prostaglandin pathways or may be involved in inactivation of nitric oxide produced during hypercapnia. 
Acknowledgments. The authors thank Candace Berryman for her excellent secretarial assistance and Stephan Bullock for his excellent technical assistance.

\section{REFERENCES}

1. Leffler CW, Busija DW. Mirro R. Armstead WM, Beasley DG 1989 Effects of ischemia on brain blood flow and oxygen consumption of newborn pigs. Am J Physiol 257:H1917-H1926

2. Kirsch JR, Helfaer MA. Blizzard K. Toung TJ, Traystman RJ 1990 Agerelated cerebrovascular response to global ischemia in pigs. Am $\mathrm{J}$ Physio 259:H1551-H1558

3. Helfaer MA, Kirsch JR, Haun SE, Koehler RC, Traystman RJ 1991 Agerelated cerebrovascular reactivity to $\mathrm{CO}_{2}$ after cerebral ischemia in swine Am J Physiol 260:H1482-H1488

4. Leffler CW, Busija DW, Armstead WM, Mirro R, Beasley DG 1989 Ischemia alters cerebral vascular responses to hypercapnia and acetylcholine in piglets. Pediatr Res 25:180-183

5. Leffler CW, Beasley DG, Busija DW 1989 Cerebral ischemia alters cerebral microvascular reactivity in newborn pigs. Am J Physiol 257:H266-H271

6. Leffler CW. Mirro R. Armstead WM. Shibata M 1992 Topical arachidonic acid restores pial arteriolar dilation to hypercapnia of postischemic newborn pig brain. Am J Physiol 263:H746-H751

7. Needleman P, Turk J, Jakschik BA. Morrison AR, Lefkowith JB 1986 Arachidonic acid metabolism. Annu Rev Biochem 55:69-102

8. Nelson CW, Wei EP, Povlishock JT, Kontos HA. Moskowitz MA 1992 Oxygen radicals in cerebral ischemia. Am J Physiol 263:H1356-H1362

9. Heymann MA, Payne BD. Hoffman JI, Rudolph AM 1977 Blood flow measurements with radionuclide-labeled particles. Prog Cardiovasc Dis 20:55-79

10. Crapo JD, McCord JM. Fridovich I 1978 Preparation and assay of superoxide dismutases. Methods Enzymol 53:382-393

11. McCord JM, Fridovich I 1969 Superoxide dismutase. An enzymic function for erythrocuprein (hemocuprein). J Biol Chem 244:6049-6055

12. Wilson DA, Traystman RJ, Rapela CE 1985 Transient analysis of the canine cerebrovascular response to carbon dioxide. Circ Res 56:596-605

13. Wagerle LC. Mishra OP 1988 Mechanism of $\mathrm{CO}_{2}$ response in cerebral arteries of the newborn pig: role of phospholipase. cyclooxygenase, and lipoxygenase pathways. Circ Res 62:1019-1026

14. Kuehl FA, Jr, Egan RW, Humes JL 1981 Prostaglandin cyclooxygenase. Prog Lipid Res 20:97-102

15. Beckman JS, Minor RL, Jr. White CW, Repine JE, Rosen GM, Freeman BA 1988 Superoxide dismutase and catalase conjugated to polyethylene glyco increases endothelial enzyme activity and oxidant resistance. J Biol Chem 263:6884-6892

16. Armstead WM, Mirro R, Busija DW, Leffler CW 1988 Postischemic generation of superoxide anion by newborn pig brain. Am J Physiol 255: $\mathrm{H} 401-\mathrm{H} 403$

17. Mickel HS, Vaishnav YN, Kempski O, von Lubitz D. Weiss JF, Feuerstein G 1987 Breathing $100 \%$ oxygen after global brain ischemia in Mongolian gerbils results in increased lipid peroxidation and increased mortality. Stroke 18:426-430
18. Yusa T, Beckman JS, Crapo JD, Freeman BA 1987 Hyperoxia increases $\mathrm{H}_{2} \mathrm{O}_{2}$ production by brain in vivo. J Appl Physiol 63:353-358

19. Wei EP, Christman CW, Kontos HA, Povlishock JT 1985 Effects of oxygen radicals on cerebral arterioles. Am J Physiol 248:H157-H162

20. Leffler CW, Busija DW, Armstead WM, Shanklin DR, Mirro R, Thelin O 1990 Activated oxygen and arachidonate effects on newborn cerebral arterioles. Am J Physiol 259:H1230-H1238

21. Chan PH, Schmidley JW, Fishman RA, Longar SM 1984 Brain injury, edema, and vascular permeability changes induced by oxygen-derived free radicals. Neurology $34: 315-320$

22. Uyama O, Shiratsuki N, Matsuyama T, Nakanishi T, Matsumoto Y, Yamada T. Narita M. Sugita M 1990 Protective effects of superoxide dismutase on acute reperfusion injury of gerbil brain. Free Radic Biol Med 8:265-268

23. Iadecola $C 1992$ Does nitric oxide mediate the increases in cerebral blood flow elicited by hypercapnia? Proc Natl Acad Sci USA 89:3913-3916

24. Gryglewski RJ, Palmer RM, Moncada S 1986 Superoxide anion is involved in the breakdown of endothelium-derived vascular relaxing factor. Nature 320:454-456

25. Haun SE, Kirsch JR, Helfaer MA, Kubos KL, Traystman RJ 1991 Polyethylene glycol-conjugated superoxide dismutase fails to augment brain superoxide dismutase activity in piglets. Stroke 22:655-659

26. Salvemini D. de Nucci G. Sneddon JM. Vane JR 1989 Superoxide anions enhance platelet adhesion and aggregation. Br J Pharmacol 97:1145-1150

27. Suzuki M, Inauen W, Kvietys $P R$, Grisham MB, Meininger $C$, Schelling ME Granger HJ, Granger DN 1989 Superoxide mediates reperfusion-induced leukocyte-endothelial cell interactions. Am J Physiol 257:H1740-H1745

28. Lefler CW, Mirro R, Armstead WM, Shibata M 1992 Attenuation by ischemia of hypercapnic cerebral vasodilation in piglets: effects of antioxidant pretreatment and arachidonate posttreatment. Pediatr Res 31:209A(abstr)

29. Helfaer MA Kirsch JR Hurn PD. Blizzard KK, Koehler RC Traystman R 1992 Tirilazad mesylate does not improve early cerebral metabolic recovery following compression ischemia in dogs. Stroke 23:1479-1486

30. Natale JE. Schott RJ, Hall ED. Braughler JM. D'Alecy LG 1988 Effect of the aminosteroid U74006F after cardiopulmonary arrest in dogs. Stroke 19:1371-1378

31. Rosenberg AA, Murdaugh E, White CW 1989 The role of oxygen free radicals in postasphyxia cerebral hypoperfusion in newborn lambs. Pediatr Res 26:215-219

32. Helfaer MA. Kirsch JR, Haun SE. Moore LE. Traystman RJ 1991 Polyethylene glycol conjugated superoxide dismutase fails to blunt post-ischemic reactive hyperemia. Am J Physiol 261:H548-H553

33. Schurer L, Grogaard B, Gerdin B, Arfors KE 1990 Superoxide dismutase does not prevent delayed hypoperfusion after incomplete cerebral ischaemia in the rat. Acta Neurochir 103:163-170

34. Matsumiya N, Koehler RC, Kirsch JR. Traystman RJ 1991 Conjugated superoxide dismutase reduces extent of caudate injury after transient focal ischemia in cats. Stroke 22:1193-1200

35. Imaizumi S, Woolworth V, Fishman RA, Chan PH 1990 Liposome-entrapped superoxide dismutase reduces cerebral infarction in cerebral ischemia in rats. Stroke 21:1312-1317

36. Chan PH, Longar S. Fishman RA 1987 Protective effects of liposome-entrapped superoxide dismutase on posttraumatic brain edema. Ann Neurol $21: 540-547$ 